\title{
Leave no stone unturned in case of groans
}

\author{
Robert J Hoekstra, ${ }^{1}$ Niels Smakman, ${ }^{1}$ Floris B M Sanders, ${ }^{2}$ Lenneke E M Haas ${ }^{3}$
}

1 Department of Surgery, Diakonessenhuis Utrecht Utrecht, The Netherlands ${ }^{2}$ Department of Radiology, Diakonessenhuis Utrecht, Utrecht, The Netherlands ${ }^{3}$ Department of Intensive Care, Diakonessenhuis Utrecht, Utrecht, The Netherlands

\section{Correspondence to} Lenneke Haas,

lennekehaas@hotmail.com
CrossMark

To cite: Hoekstra RJ, Smakman N, Sanders FBM et al. BMJ Case Rep Published online: [please include Day Month Year] doi:10.1136/bcr-2013201991

\section{DESCRIPTION}

An 84-year-old woman presented to our emergency room with abdominal symptoms since a couple of weeks. She reported vomiting and absence of defaecation for 3 days. Her medical history revealed myocardial infarction and an appendectomy. Physical examination was unremarkable, except for a distended abdomen and hypoactive bowel sounds.

An abdominal CT scan revealed air in the intrahepatic gall ducts and ductus choledochus (pneumobilia), dilated bowels, an occluding gallstone and some smaller gallstones in the proximal ileum (figure 1). She underwent an emergency laparotomy with successful enterolithotomy (figure 2).

A gallstone ileus is caused by a gallstone that mechanically occludes the intestines. It is a rare complication of cholelithiasis and occurs in less than $0.5 \%$ of patients, but accounts for $25 \%$ of the small bowel obstructions in patients over 65 years of age. After inflammation of the gall bladder and adherence to a close bowel, mostly the duodenum (60\%), a biliary enteric fistula can be formed. The passage of large gallstones can result in obstruction, most frequently $(50-70 \%)$ in the ileum, since it is the narrowest segment of the intestine. Pneumobilia is seen in $30-60 \%$. Since age and female sex are major risk factors for the development of gallstones, gallstone ileus is mostly seen in the elderly with a female preponderance. ${ }^{1}$

The spontaneous passage of a stone is rare. Enterolithotomy is the cornerstone of treatment.

Concomitant cholecystectomy, fistula division and common bile duct exploration can be considered, but high-risk patients can be managed by stone extraction only, since the risk for recurrent gallstone ileus or cholecystitis is low. ${ }^{2}$
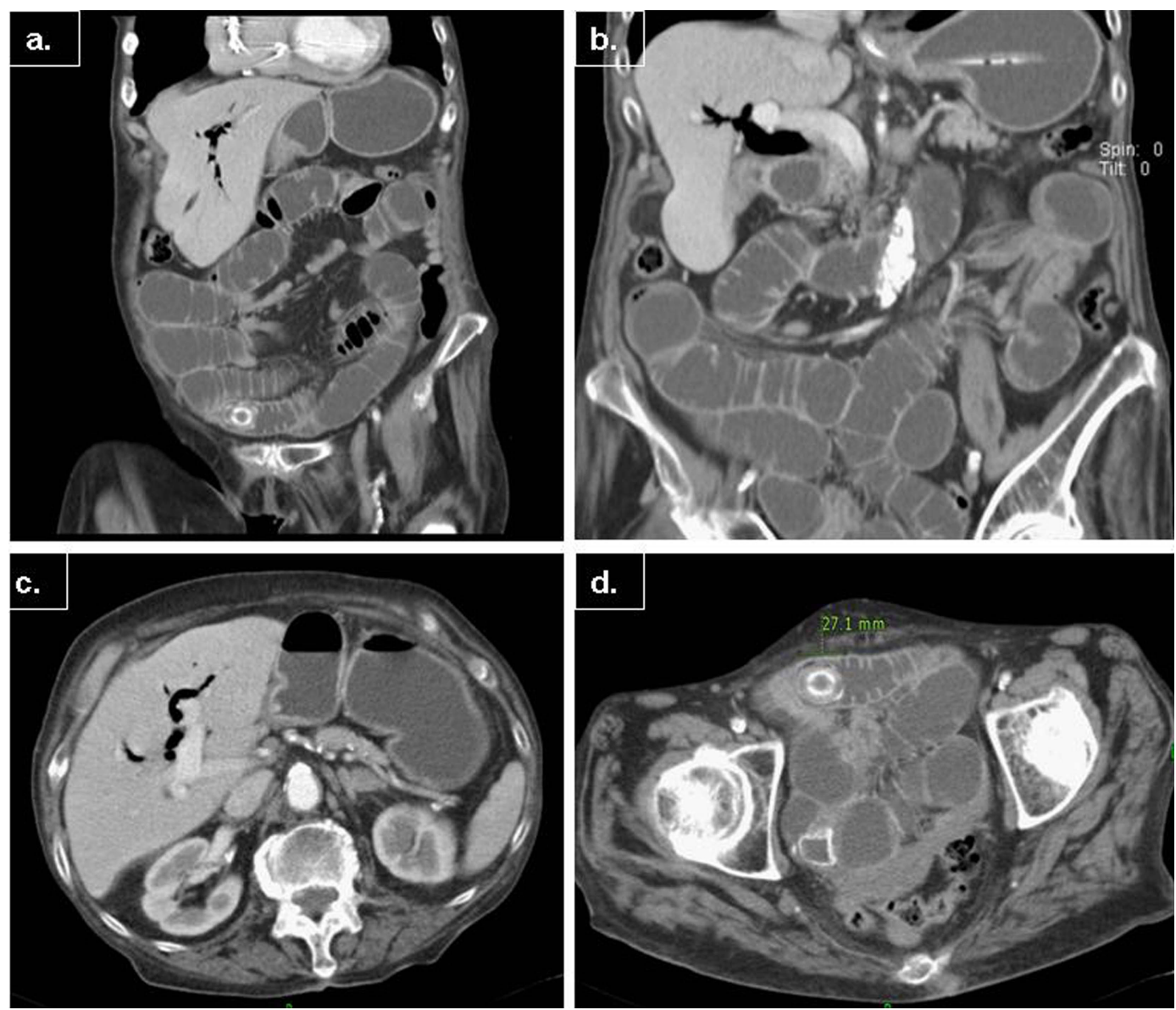

Figure 1 (A-D) Abdominal CT scan showing air in the intrahepatic gall ducts and ductus choledochus (pneumobilia), dilated small bowels, an occluding gallstone $(27 \mathrm{~mm}$ ) and some smaller gallstones (altogether $37 \mathrm{~mm}$ ) in the proximal ileum (A-B: coronal and C-D: transverse plane). 

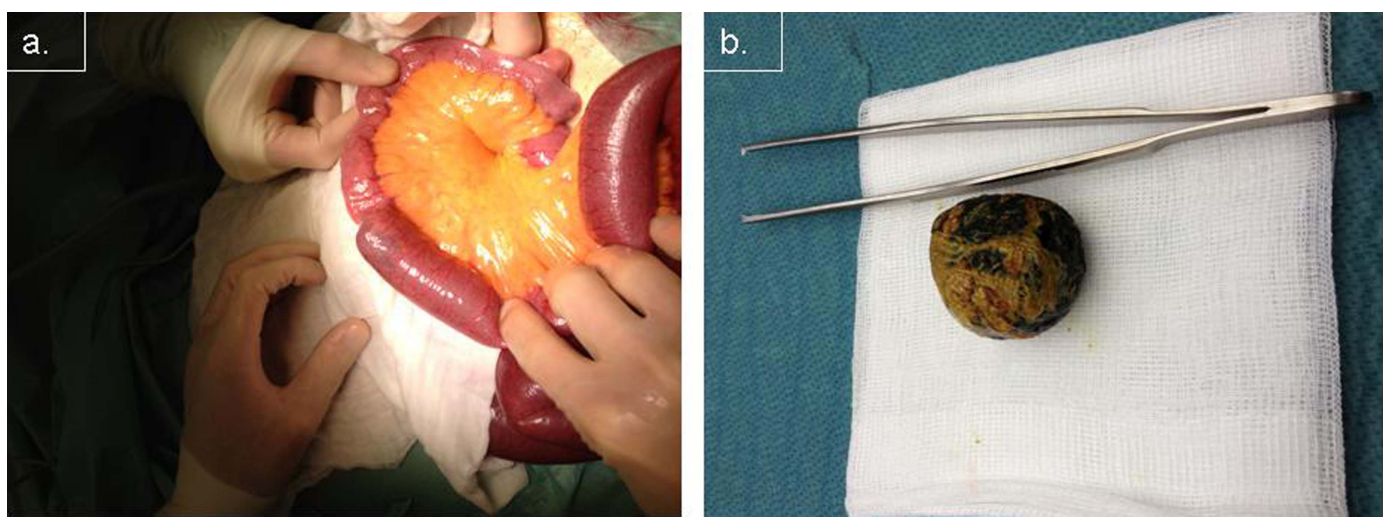

Figure 2 (A) Intraoperative image of the ileum with a clear change in the bowel calibre. (B) The gallstone after extraction.

\section{Learning points}

- Gallstone ileus is an unusual complication of cholelithiasis and occurs mostly in the elderly, with a female preponderance.

- Early diagnosis is important. A strong index of suspicion is essential. Gallstone ileus should always be in the differential diagnosis when assessing an elderly person with intestinal obstruction. Pneumobilia occurs in $30-60 \%$, although it is not a specific sign of gallstone ileus.

- Surgery is the cornerstone of gallstone ileus management, but despite adequate treatment, gallstone ileus is still associated with relatively high rates of morbidity and mortality.
Competing interests None.

Patient consent Obtained.

Provenance and peer review Not commissioned; externally peer reviewed.

\section{REFERENCES}

1 Ayantunde AA, Agrawal A. Gallstone ileus: diagnosis and management. World I Surg 2007;6:1292-7.

2 Halabi WJ, Kang CY, Ketana N, et al. Surgery for gallstone ileus: a nationwide comparison of trends and outcomes. Ann Surg. Published Online First: 4 Jan 2013. doi:10.1097/SLA.0b013e31827eefed

Copyright 2013 BMJ Publishing Group. All rights reserved. For permission to reuse any of this content visit http://group.bmj.com/group/rights-licensing/permissions.

BMJ Case Report Fellows may re-use this article for personal use and teaching without any further permission.

Become a Fellow of BMJ Case Reports today and you can:

- Submit as many cases as you like

- Enjoy fast sympathetic peer review and rapid publication of accepted articles

- Access all the published articles

- Re-use any of the published material for personal use and teaching without further permission

For information on Institutional Fellowships contact consortiasales@bmjgroup.com

Visit casereports.bmj.com for more articles like this and to become a Fellow 